\title{
CULTURA CORPORAL LUTAS EM AULAS DE EDUCAÇÃO FÍSICA ESCOLAR: DESAFIOS E POSSIBILIDADES
}

\author{
Deise Bastos de Araújo \\ deisetkd@hotmail.com
}

\begin{abstract}
RESUMO
Com o objetivo de apresentar os desafios e possibilidades de disseminação da cultura corporal lutas em escolas da educação básica, este artigo de revisão bibliográfica traz no bojo das discussões as principais legislações vigentes no Brasil, pesquisas em diferentes realidades e bem como estratégias de intervenção. Com isto, foi possível identificar que, mesmo sendo reconhecida como elemento fundamental para a formação autônoma crítica e reflexiva do público atendido em instituições de ensino, o Ensino das Lutas, ainda é pouco disseminado nas escolas, por diferentes fatores que variam desde a formação de professores a investimentos em recursos materiais. Assim, podendo concluir que as dificuldades existentes precisam ser discutidas e refletidas no âmbito educacional, além disto que sejam elaboradas políticas públicas educacionais que subsidiem com eficiência as práxis pedagógicas, dando o suporte necessário e assim promovendo educação com qualidade.
\end{abstract}

Palavras-Chave: Cultura Corporal Lutas; Desafios; Educação Física Escolar; possibilidades.

\begin{abstract}
In order to present the challenges and possibilities of disseminating body culture struggles in schools of basic education, this bibliographic review article brings together the main legislation in force in Brazil, research in different realities and intervention strategies. With this, it was possible to identify that, even though it is recognized as a fundamental element for the autonomous critical and reflective formation of the public served in educational institutions, the Teaching of Struggles is still little disseminated in schools, due to different factors that vary from the formation teachers to invest in material resources. Thus, being able to conclude that the existing difficulties need to be discussed and reflected in the educational scope, in addition to the elaboration of public educational policies that efficiently subsidize the pedagogical praxis, providing the necessary support and thus promoting quality education.
\end{abstract}

Key words: Body Culture Struggles; Challenges; School Physical Education; possibilities.

\section{RESUMEN}

Con el objetivo de presentar los desafíos y posibilidades de difusión de las luchas de la cultura corporal en las escuelas de educación básica, este artículo de revisión 
bibliográfica trae al corazón de las discusiones la principal legislación vigente en Brasil, la investigación en diferentes realidades y estrategias de intervención. Con ello se pudo identificar que, si bien se reconoce como un elemento fundamental para la formación autónoma crítica y reflexiva del público atendido en las instituciones educativas, la Enseñanza de las Luchas, aún está poco difundida en las escuelas, debido a diferentes factores que van desde la formación de profesores hasta invertir en recursos materiales. Así, pudiendo concluir que las dificultades existentes necesitan ser discutidas y reflejadas en el ámbito educativo, además de la elaboración de políticas públicas educativas que subsidien de manera eficiente la praxis pedagógica, brindando el apoyo necesario y promoviendo así una educación de calidad.

Palabras clave: Luchas por la cultura corporal; Desafíos; Educación Física Escolar; posibilidades.

\section{INTRODUÇÃO}

O movimento é elemento vital para o ser humano, através deste é possível desenvolver ações cotidianas que são primordiais para a sua sobrevivência, possibilitando a locomoção, a realização de atividades diversificadas, interação com o outro, autoconhecer-se, dentre outros aspectos epistemologicamente construídos ao longo de sua existência.

Diante disto, muitas são as possibilidades de movimentar-se e a sistematização destas habilidades, formam sequencias de atividades que ao longo dos tempos vão atribuindo valores culturais e estruturando-se enquanto práticas corporais de um determinado povo e ganhando outras dimensões territoriais.

Em meio a tantas estruturações do movimento, eis que surge a prática das lutas, que emergem das necessidades de sobrevivência da humanidade nos primórdios, a partir de embates contra animais predadores, de conquista de território, na busca por alimentos, dentre outras.

E com o passar dos tempos, estes movimentos foram organizados e sistematizados, dando origem a uma ampla gama de modalidades de lutas, artes marciais e esportes de combate, que fazem parte da cultura humana até os tempos atuais.

Com isto, tornando-se a cultura corporal lutas em atividades educativas rica em contexto histórico, cultural e social, que passa a ser vista como uma importante ferramenta de ensino e aprendizagem, para pessoas de qualquer faixa etária. 
Desta forma, ganhando lugar em diferentes espaços de convivência, como ocorreu nas escolas, em que as lutas passou a ser reconhecida legalmente como um dos eixos norteadores da Educação Física Escolar.

Sendo parte do currículo escolar, as lutas muito tem a contribuir para o processo de formação do público da educação básica, em que através de conteúdos programáticos é capaz de proporcionar trocas de experiências teóricas e práticas essenciais para a construção de seres autônomos, críticos e reflexivos.

Assim, este artigo tem o objetivo de apresentar os desafios e possibilidades de disseminação da cultura corporal lutas em escolas da educação básica. Com a finalidade de ampliar o acervo deste conteúdo e contribuir para a reflexão crítica dos leitores.

\section{MÉTODOS}

Este é um artigo de revisão bibliográfica, que traz no bojo das discussões as principais legislações vigentes no Brasil, pesquisas em diferentes realidades, bem como estratégias de intervenção para a aplicabilidade do Ensino das Lutas em aulas de Educação Física Escolar, sob a ótica de diferentes autores.

\section{ANÁLISE E DISCUSSÃo}

A educação física é uma das disciplinas que compõe a matriz curricular da educação básica, assim com as demais disciplinas, esta deve garantir a formação integral dos alunos, de modo que contribua para autonomia e desenvolvimento da criticidade.

Sobre a Educação Física, os Parâmetros Nacionais Curriculares (PCNs) propõe:

[...] democratizar, humanizar e diversificar a prática pedagógica da área, buscando ampliar, de uma visão apenas biológica, para um trabalho que incorpore as dimensões afetivas, cognitivas e socioculturais dos alunos. Incorpora, de forma organizada, as 
principais questões que o professor deve considerar no desenvolvimento de seu trabalho, subsidiando as discussões, os planejamentos e as avaliações da prática de Educação Física (BRASIL, p. 15, 1998).

Enquanto área de conhecimento que tem o corpo em movimento como objeto de estudo, e atrelado a isto, conteúdos como danças, jogos, esportes, ginásticas e lutas, a Educação Física, deve garantir o direito dos alunos em terem acesso a estas diferentes manifestações da cultura corporal do movimento.

Em outras palavras, a negação de oferta de oportunidades de vivências diversificadas é infringir e limitar o acesso ao processo de ensino aprendizagem integral aos escolares.

Tanto é que, a Nova Base Nacional Comum Curricular (BNCC), documento normativo que apresenta as aprendizagens essenciais para a educação básica, dispõe de Unidades Temáticas e que para o trato com a Educação Física, no contexto das Lutas, sinaliza que:

A unidade temática Lutas $^{42}$ focaliza as disputas corporais, nas quais os participantes empregam técnicas, táticas e estratégias específicas para imobilizar, desequilibrar, atingir ou excluir o oponente de um determinado espaço, combinando ações de ataque e defesa dirigidas ao corpo do adversário. Dessa forma, além das lutas presentes no contexto comunitário e regional, podem ser tratadas lutas brasileiras (capoeira, huka-huka, luta marajoara etc.), bem como lutas de diversos países do mundo (judô, aikido, jiu-jítsu, muay thai, boxe, chinese boxing, esgrima, kendo etc.) (BRASIL, p. 218, 2018).

Porém, fato é que em muitas escolas brasileiras despontam uma realidade contraditória em relação as propostas das leis que regem a educação, pois infelizmente "as lutas se constituem como um dos temas da Educação Física escolar que encontram maior resistência por parte dos professores, havendo preconceitos em relação ao seu ensino" (HEGELE et al, p. 2, 2018),

Muitas vezes o ensino das lutas não acontecem por inúmeras barreiras, dentre estas, Ferreira (2006) observa que:

[...] os profissionais necessitam de treinamento, de capacitação e de cursos de reciclagem, para, a partir de então, incluir a prática das lutas em suas aulas. Também se pode concluir que alguns profissionais possuem uma visão deturpada do que sejam as lutas, relacionando-as com violência e com agressividade, atitude oposta à educação física e à própria filosofia das lutas (FERREIRA, p. 44, 2006). 
Embora haja deficiência neste ensino, o contexto das lutas se faz presente na realidade das pessoas, sejam por meio das mídias, das práticas corporais extraescolares, no jogos eletrônicos, etc.

Haja vista que o conteúdo de lutas provoca fascínio e curiosidade por conta dos alunos, dentro e fora da escola, como consta numa pesquisa realizada por Rodrigues et al (2017) em que constaram que:

[...] uma quantidade expressiva de alunos gostaria que as lutas fossem utilizadas como conteúdo da educação física escolar. Com a influência da mídia, as práticas de autodefesa e como forma de esporte foram bastante citadas pelos escolares (RODRIGUES et al, p. 8, 2017).

Assim sendo de fundamental relevância considerar que, embora os desafios existam, os profissionais envoltos precisam sair da zona de conforto e tentar de diferentes maneiras trazer este recurso de ensino para o 'chão da sala de aula'.

Diante dos apontamentos supracitados, é preciso refletir e repensar as práticas docentes, as políticas vigentes, o currículo escolar e os anseios dos educandos, para tanto, pensar nas possibilidades é ampliar olhares para propagar, dentro da viabilidade e papel de cada ator, em todo o processo envolto do ensino e da aprendizagem.

Muitos questionamentos são feitos por docentes a respeito de como trabalhar o conteúdo de lutas nas escolas, uma inquietação, que pode ser desvelada por Rufino e Darido (2015) sob a seguinte perspectiva:

[...] há uma escassez de materiais didáticos acerca do conteúdo das lutas que apresentam uma perspectiva crítica e organizada de como ensinar estas práticas nas aulas de Educação Física sem serem concebidos, necessariamente, como manuais de atividades (RUFINO, DARIDO, p. 514, 2015).

Diante da diversidade metodológica que pode-se trabalhar com o conteúdo de lutas, se faz indispensável:

[...] a importância de abranger nos processos de ensino e aprendizagem as dimensões do conteúdo conceitual, procedimental e atitudinal, possibilitando assim à disciplina de Educação Física ir além de seus ensinamentos de caráter "procedimental", ou seja, ultrapassando os limites da "prática", contribuindo desse modo para uma aprendizagem significativa e uma educação integral, que busque desenvolver nos alunos amplas habilidades e competências, tornando-os protagonistas no processo educativo. Por exemplo, ao priorizar nas aulas aspectos relacionados às relações interpessoais, sociais e culturais, busca-se garantir um ensino que oportuniza ao aluno o exercício da cidadania em seu contexto social (DOIRADO, p.109, 2020). 
Vale ressaltar que, estas dimensões de ensino não devem estar dissociadas uma das outras, mas que estas estejam conectadas entre si, ou seja, não se deve trabalhar cada dimensão de forma isolada, mas de forma integrada. E com isto, propor aos alunos experiências valiosas, pois:

[...] a tarefa da escola vai além da simples apropriação ou execução de golpes, movimentos, gestos técnicos, enfim, os procedimentos estabelecidos. Sendo assim, ensinar as lutas é muito mais do que ensinar os alunos a submeterem seus companheiros por meio de golpes ou movimentos de oposição; ensinar as lutas transcende os movimentos e gestos. Ensinar as lutas é ampliar a visão sobre elas, possibilitando que sejam adquiridas novas visões e novos olhares a respeito dessa temática. Isso só é possível através da ampliação dos conteúdos (RUFINO, DARIDO, p. 18, 2013).

\section{CONSIDERAÇÕES FINAIS}

Mediante ao apresentado, faz-se indispensável a elaboração de políticas públicas educacionais eficientes, nas quais subsidiem as práxis pedagógicas nas Unidades Educacionais, como formações continuadas, recursos didático pedagógicos, orientações assertivas e apoio a fruição do elementos lutas na escolas.

Haja vista que, um outro fator precisa ganhar destaque, como a formação inicial dos docentes atuantes com educação física, que estes tenham na tríade da educação superior (ensino, pesquisa e extensão) subsídios pedagógicos que os preparem e os sensibilizem para a concretização das aprendizagens das diferentes manifestações da cultura corporal do movimento no seu campo de trabalho, incluindo na matriz curricular e no projeto pedagógico de curso, conteúdos e disciplinas que abordem o Ensino das Lutas.

Além disto, que na educação básica as aulas de Educação Física sejam ministradas por profissionais formados em educação física, que esta não tenha trato diferenciado ou inferiorizado em relação as demais áreas de conhecimento, mas que esta esteja em consonância com as demais.

É preciso também, que os docentes atuantes com a disciplina de Educação Física, sejam encorajados e estimulados a exercerem seu papel com cidadania e respeito as especificidades da disciplina. E que dentro das possibilidades, adaptem aos interesses e necessidades educacionais, incluindo no processo de ensino 
aprendizagem todos os conteúdos que norteiam a Educação Física, neste atributos destacando as Lutas.

Contudo, ficando como sugestão a ampliação da participação da sociedade como um todo, nas discussões e elaboração das políticas públicas educacionais e que também haja escuta sensível em benefício da educação de qualidade. $E$, que mais pesquisas sejam desenvolvidas e publicadas para acrescentamento do acervo científico no que tange a Cultura Corporal Lutas.

\section{REFERÊNCIAS}

BRASIL. Ministério da Educação. Base Nacional Comum Curricular. 2018. Disponível em: http://basenacionalcomum.mec.gov.br/images/BNCC El EF 110518 versaofinal sit e.pdf.

BRASIL, Parâmetros Curriculares Nacionais. Terceiro e quarto ciclos: Educação Física. Brasília: MECSEF, $1998 . \quad$ Disponível: http://portal.mec.gov.br/seb/arquivos/pdf/fisica.pdf.

DOIRADO, Edmilson Fernandes. Educação Física nos anos iniciais do Ensino Fundamental: uma abordagem metodológica de ensino do conteúdo lutas. 2020. Repositório UNESP.

FERREIRA, Heraldo Simões. As lutas na educação física escolar. Revista de Educação Física/Journal of Physical Education, v. 75, n. 135, 2006.

HEGELE, Bernhardt; GONZÁLEZ, Fernando Jaime; BORGES, Robson Machado. Possibilidades do ensino das lutas na escola: uma pesquisa-ação com professores de educação física. Caderno de Educação Física e Esporte, v. 16, n. 1, p. 99-107, 2018.

RODRIGUES, Vinícius Salomão et al. AS LUTAS NA EDUCAÇÃO FÍSICA ESCOLAR A PARTIR DA PERCEPÇÃO DOS ESTUDANTES. Revista Eletrônica Nacional de Educação Física, v. 7, n. 10, p. 2-9, 2017.

RUFINO, Luiz Gustavo Bonatto; DARIDO, Suraya Cristina. O ENSINO DAS LUTAS NAS AULAS DE EDUCÇÃO FÍSICA: ANÁLISE DA PRÁTICA PEDAGÓGICA À LUZ DE ESPECIALISTAS. Revista da educação física/UEM, v. 26, n. 4, p. 505-518, 2015.

RUFINO, Luiz Gustavo Bonatto; DARIDO, Suraya Cristina. Possíveis diálogos entre a educação física escolar e o conteúdo das lutas na perspectiva da cultura corporal. Conexões, v. 11, n. 1, p. 144-170, 2013. 